\title{
Bus Transit Network Structure Selection With Multiple Objectives
}

\author{
K. Ramacandra Rao, Indian Institute of Technology, Delhi, India \\ Subhro Mitra, University of North Texas at Dallas, USA \\ Joseph Szmerekovsky, North Dakota State University, USA
}

\begin{abstract}
Bus transportation is the essential mode of public transportation available for intra-district movements in India. The planning of different stages of bus transportation planning is usually done in an adhoc manner on the basis of the experience of the operators. For a rational design of the bus transit system, it is essential to take into account the objectives of different interest groups. Selection of an appropriate network structure is an essential part of the planning process. In this paper, a model developed for generating a number of alternative network structures using link deletion concept is presented. One of these alternatives can be selected on the basis of the trade-off between the user and operator objectives. The model has been applied to a case study of bus transit network of Visakhapatnam region in Andhra Pradesh.
\end{abstract}

\section{KEYWORDS}

Bus Transportation, Multiobjective, Network Structures, Programming, Public Transportation

\section{INTRODUCTION}

The planning of regional bus routes that operate in India is based mostly on the experience of the operator, public or private. The route decisions taken quite often lead to overcrowding in certain routes and under-utilization in the others. Attempts to improve this situation by increasing the frequency of buses along the overcrowded routes and reducing the same from the non-profitable routes have not always met with success. The State Road Transport Corporations (SRTCs), the major operators of regional bus services in India, have rarely considered redesigning the existing bus networks to improve their performance. In the regional bus transportation planning process, there are two major groups of stakeholders. They are SRTCs or bus operators and the users. The users' objective is to minimize the cost or time of travel. The operators' objective is to maximize the earnings (which can be represented by passenger-kilometers). The routes also have to be viable financially. Often, these interests are in conflict. Thus, there is a need to develop a methodology for the planning of regional bus routes considering both users' and operators' interests.

If the network structure is not correctly selected, the routes generated tend to be inefficient. Therefore, there is a need to develop a methodology for the selection of links that form the network. Passenger flow concentration is a stage of transit planning process that decides the network structure to be used before the selection of routes can be taken up. In general, denser (fine meshed) transit networks require more bus fleet as the number of routes will be more. In this case, the user can always be guaranteed travel on the shortest path while the operator has to run more number of routes. In 
the sparse (coarse) meshed network, the operator can serve more demand with lesser fleet size. But the users will have to take detour increasing their travel costs. Thus, the multiobjective nature of the passenger flow concentration stage is evident.

This paper presents a model for passenger flow concentration with multiple objectives. The relevance of multiobjective analysis in bus transit network planning is discussed in Section 2. The details of the model developed are presented in Section 3. The application of the model to a case study is presented in Section 4. Conclusions are presented in Section 5.

\section{MULTIOBJECTIVE ANALYSIS IN TRANSIT NETWORK PLANNING AND DESIGN}

An exhaustive review of the multiobjective transportation network design problems was given by Current and Marsh (1993) and Current and Min (1986). The objectives formulated or suggested in these reviews address transportation costs, construction costs, distance, travel time, inventory, safety, household relocation, demand satisfaction, accessibility, quality, flexibility and reliability of service, facility utilization, profit, economic development and environmental concerns among others. The complexity of the objectives and the difficulty or impossibility of measuring them in commensurate units are also evident from these reviews. In general, multiobjective analysis is designed for problems in which the objectives cannot be readily measured in commensurate units. Moreover, multiobjective programming and planning is concerned with decision making problems on which there are several conflicting objectives (Cohon1978).

The model given by Rea (1972) is possibly the first of its kind that gives an assignment type of model for passenger flow concentration. This model takes advantage of the special characteristics of public transportation systems. It allows the planner to explore easily the combination of modes as a tool for generating and planning public transportation networks. The aim of the flow concentration model is to leave out some of the links with low flows. A similar approach was suggested by Hasselström (1981). Marwah et al. (1984) proposed a method that minimizes the total operation and riding time cost of the network. Carraresi et al. (1996), proposed a mathematical programming model for the regional mass transit (bus and rail) assignment. This model aims at improving the effectiveness of the mass transit system by modifying the departure trips taking into account the feasibility of the vehicle and driver schedules. Blue et al. (1997) presented a bi-objective path search algorithm. The objectives considered by this algorithm are travel time and trip complexity. Subsequently a tradeoff parameter is used to generate non-dominated solutions that can help in in-vehicle route guidance systems (IVRGS).

Steenbrink (1974) and Magnanti and Wong (1984) proposed models for optimization of transportation networks. These models select the best links from a given network based on some desired objective. These are often called as optimal network problems and are similar to passenger flow concentration models. Some optimization models for passenger flow concentration are given by Billheimer and Gray (1973) and Dubois et al. (1979).

The optimal network problem (ONP) in its generalized form can be represented as follows:

Minimize $T=\sum_{(i, j) \in N^{2}} D_{i j} t_{i j}(X)$

Subject to $\sum_{(i, j) \in \bar{A}} C_{i j} x_{i j} \leq C_{T}$ 
where, $G(N, \bar{A})=$ graph of the network representing a set of streets $\bar{A}$ having $N$ nodes,

$x_{i j}=\left\{\begin{array}{l}1, \text { if the link } i-j \text { is chosen } \\ 0, \text { otherwise }\end{array} \quad \forall(i, j) \in \bar{A}\right.$

$T=$ total travel time of the network

$D_{i j}=$ demand between nodes $i$ and $j$

$t_{i j}^{i j}(X)=$ travel time between nodes $i$ and $j$

$C_{i j}=$ cost of adding a street to a network

$C=\sum_{(i, j) \in \bar{A}} C_{i j}$, investment cost for using the street network.

$C_{T}=$ maximal cost allowed for modifying the street network

The solution of this problem is obtained by explicit enumeration method. Computational experience has revealed that these methods have practical limitations (networks with up to 30 nodes are solved) although they are theoretically established (Johnson et al, 1978). This is due to the non-polynomial (NP-complete) time complexity of the problem. Also, the travel times are to be recomputed each time a link is added or removed. This computation is time consuming, especially for a link removal as the shortest paths can be unexpectedly modified and have to be re-determined. Practically, optimum search methods become intractable as soon as the number of nodes exceed ten, which happens in real sized networks.

Heuristic methods can possibly offer satisfactory solutions, when the size of the network is large (Magnanti and Wong 1984). These methods try to minimize the sum of $T+C$. There are two types of procedures, of which one class is greedy type involving link removals and the other is of link addition type. The main features of the greedy type of algorithms can be outlined as follows. At each step of the procedure, a search is carried out among the remaining links to determine the link, which if removed, will provide the best network in terms of the total travel time. Unfeasibility of the solution obtained is checked. When the solution becomes feasible, the algorithm stops. Otherwise it proceeds to another step. The link addition algorithm works as follows (Wong 1980). First, a tree joining every node is built heuristically. At each step, a node is identified whose demand for joining the already built part of the tree is maximal. The joining path is thus searched which minimizes average total travel time.

From the review of literature presented in the preceding paragraphs it is evident that the passenger flow concentration models are generally of assignment type. In addition to this, the following features are desired.

- Multiple objectives are to be considered.

- The preferences of the operator and user are also to be incorporated.

- The network chosen should be connected.

- The solution procedure of the model should not be computationally burdensome.

Keeping these considerations in view, a model for the passenger flow concentration (PASFLOW) is developed.

\section{PASSENGER FLOW CONCENTRATION MODEL (PASFLOW)}

\subsection{Selection of Objectives}

The major interest groups involved in the planning and operation of regional bus transit services in India are operators and users. The operators' objective is to maximize the earnings. The users' 
objective is to travel on the least cost path. The quantification of the users' and operators' objectives is done as follows:

Operator Objective: A measure of the earnings at the network level, when the fleet size and other requirements are not known, is the distance traveled by the passengers. The operators' objective chosen for the passenger flow concentration stage is the maximization of passenger kilometers, which is a surrogate measure of the operator earnings.

User Objective: The travel cost or time can reasonably reflect the user objective. However, this objective can be taken on a relative basis. The users have to take a detour in case of non-availability of a route on the shortest path. Thus, minimization of detour has been chosen as the users' objective.

\section{Model Formulation}

The multiobjective formulation for passenger flow concentration is given below:

$$
\text { Maximize } \mathrm{Z}=\left[\mathrm{Z}_{1}, Z_{2}\right]
$$

where

$$
Z_{1}=\sum \sum f_{i j} l_{i j} x_{i j} \text { (4) } Z_{2}=-\left[\sum \sum f_{i j} l_{i j} x_{i j}-\sum \sum f_{i j}^{0} l_{i j}\right]^{\beta}
$$

subject to the connectivity constraint

$$
\prod_{i, j \in N} x_{i j}=1
$$

where $Z=$ combined objective function

$Z_{1}=$ operator's objective function (total passenger-kilometers)

$Z_{2}=$ user's objective function; a negative sign is given as the function is being maximized when the minimum is desirable

$\beta=$ power of the detour function ( $>1.0)$

$x_{i j}=$ element of the connectivity matrix $\mathbf{X}$

$X=\bigcup_{i=1}^{N-1} B^{i}, \mathbf{B}$ is the adjacency matrix of the graph $G(N, A)$

$N=$ set of nodes in the graph

$A=$ set of links in the graph

$f_{i j}^{0}=$ flow on the link $i-j$ for the maximal network

$f_{i j}=$ flow on the link $i-j$ of the network

$l_{i j}=$ length of link $i-j$

The decision variables are the link choices $x_{i j}$ (binary variables). The index, $\beta$ can be varied so that the detour function's increase is more than that of operator's objective. So, the index value has to be greater than 1.00. If it is equal to 1.00 then there will be no feasible solution space for the multiobjective problem. Depending on the feasibility constraint the non-inferior solution set is to be identified. The final solution set is to be identified from the operator and user preferences. However, owing to the difficulty in the solution of this $0-1$ multiobjective programming problem, a heuristic solution is developed based on the concept of link deletion (Ramachandra Rao, 1998). 


\section{HEURISTIC FOR PASSENGER FLOW CONCENTRATION}

The inputs required for the model are; network structure and origin-destination (O-D) data. A link deletion strategy is followed. The shortest paths between all the O-D pairs are obtained by Floyd's Algorithm (Deo 1974). Passenger demand is assigned onto the network by all-or-nothing rule. The link loads are obtained as products of link length and link flows. The sum of all the link loads gives the total passenger kilometers (pass-km). To increase the operators' objective, the link with the lowest load is deleted. At each deletion, the feasibility with respect to connectivity is checked. If the demands are reassigned, then there will be an increase in the objective function value. The heuristic stops when the network becomes a spanning tree. Depending upon the preferences of the passenger and operator, the choice of the network to be considered can be made from the set of network configurations obtained after successive link deletions. All the links are arranged in the ascending order of magnitude of pass-km values. The link with the lowest load is removed from the network and the network connectivity is checked. If the link removal makes the network unconnected then the removed link is replaced, and the link with next higher link load is removed. After each link removal, the shortest paths are re-determined. The passenger flows are reassigned using all-or-nothing rule and the link loads are computed. For each successful link removal, objective function values are calculated. The steps followed in the heuristic are given below.

This process is repeated till the network becomes a spanning tree.

STEP 1: Find the shortest paths between all the O-D pairs of the network $\mathrm{G}(\mathrm{N}, \mathrm{A})$.

STEP 2: (i) Assign the O-D flows on the shortest paths by all-or-nothing rule and (ii) arrange the link loads in ascending order of magnitude.

STEP 3: (i) Delete the link with the lowest load value, and (ii) Check for the connectivity of the network STEP 4: (i) If the connectivity is retained remove the link permanently. The values of the total pass$\mathrm{km}$ and the detour are computed. Goto Step 3. (ii) If connectivity is not retained, replace the deleted link. Goto Step 3 to delete the link with the next higher load and (iii) If the number of replacements is equal to the number of the links in the remaining network, STOP. The flowchart for the heuristic (PASFLOW) is given in Figure 1.

Figure 1. Flowchart for Passenger Flow Concentration Algorithm

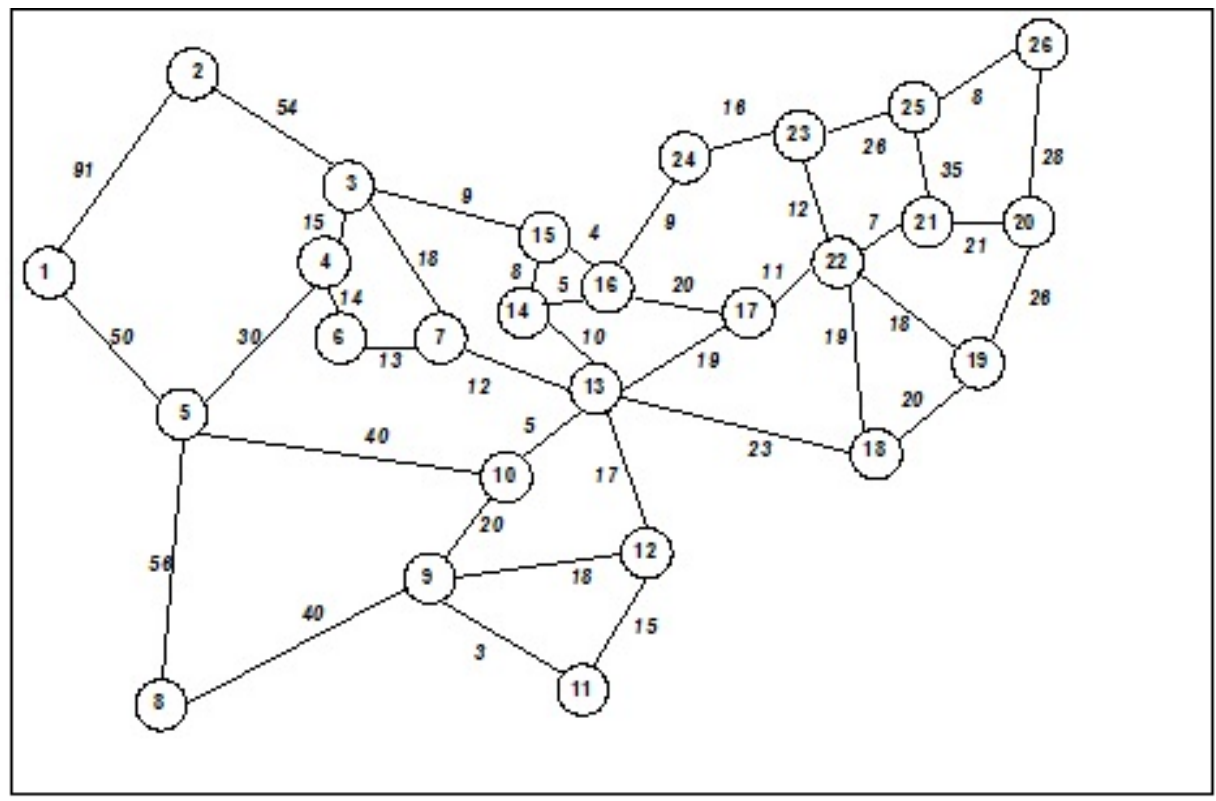




\section{APPLICATION OF THE MODEL ON THE VISAKHAPATNAM REGIONAL BUS TRANSIT NETWORK}

The case study chosen for the application of the model is the bus transit network of Visakhapatnam region. The district has a road length of $4748 \mathrm{~km}$, consisting of $136 \mathrm{~km}$ of National Highway (No. 5), $302 \mathrm{~km}$ of State Highways, $1060 \mathrm{~km}$ of Major District Roads, $1358 \mathrm{~km}$ of Other District Roads and $1892 \mathrm{~km}$ of Village Roads. The bus transportation system in the Visakhapatnam district is operated by a state owned transit agency, Andhra Pradesh State Road Transport Corporation (APSRTC). The bus transit network chosen for the study is based on the existing road network. All the main urban settlements and some important rural settlements are selected as nodes. The network obtained on this basis is shown in Figure 2. The values indicated on the links give their lengths in $\mathrm{km}$. The demand matrix for the network is estimated by carrying out trip distribution using gravity model (Kanafani 1983). The population of each node is taken as the sum of the population of the surrounding settlements. The regional trip productions at various nodes are calculated based on average trip rates. The demand matrix is given in Table 1.

Links were deleted one at a time, till the resulting network became a spanning tree. Detour function was calculated taking $\beta$ value as 1.25 using Eq. 5 as shown in Figure 3. The values of the objective functions (total pass-km and detour) along with the links removed are given in Table 2. It can be seen that both the passenger kilometers and detour increase with each link deletion.

The selection of the final network structure can be done considering the values of objective functions, i.e., total passenger-km and total detour. For an exhaustive investigation of various possible alternatives, different network structures can be considered for further analysis. Final selection of the network can be made after examining the network performance parameters of the alternatives.

In order to study the effect of various input parameters on the bus transit network performance indices, sensitivity analysis was carried out. The network of the case study was considered for this purpose. The variation of the two objective functions, total passenger-km and total detour, obtained on successive link deletions is presented in Figures 4 and 5. The set of non-inferior solutions obtained is shown in Figure 6. Given the values of the $Z_{1}$ and $Z_{2}$, the corresponding network structure can be obtained. 
Figure 2. Regional Bus Transit Network

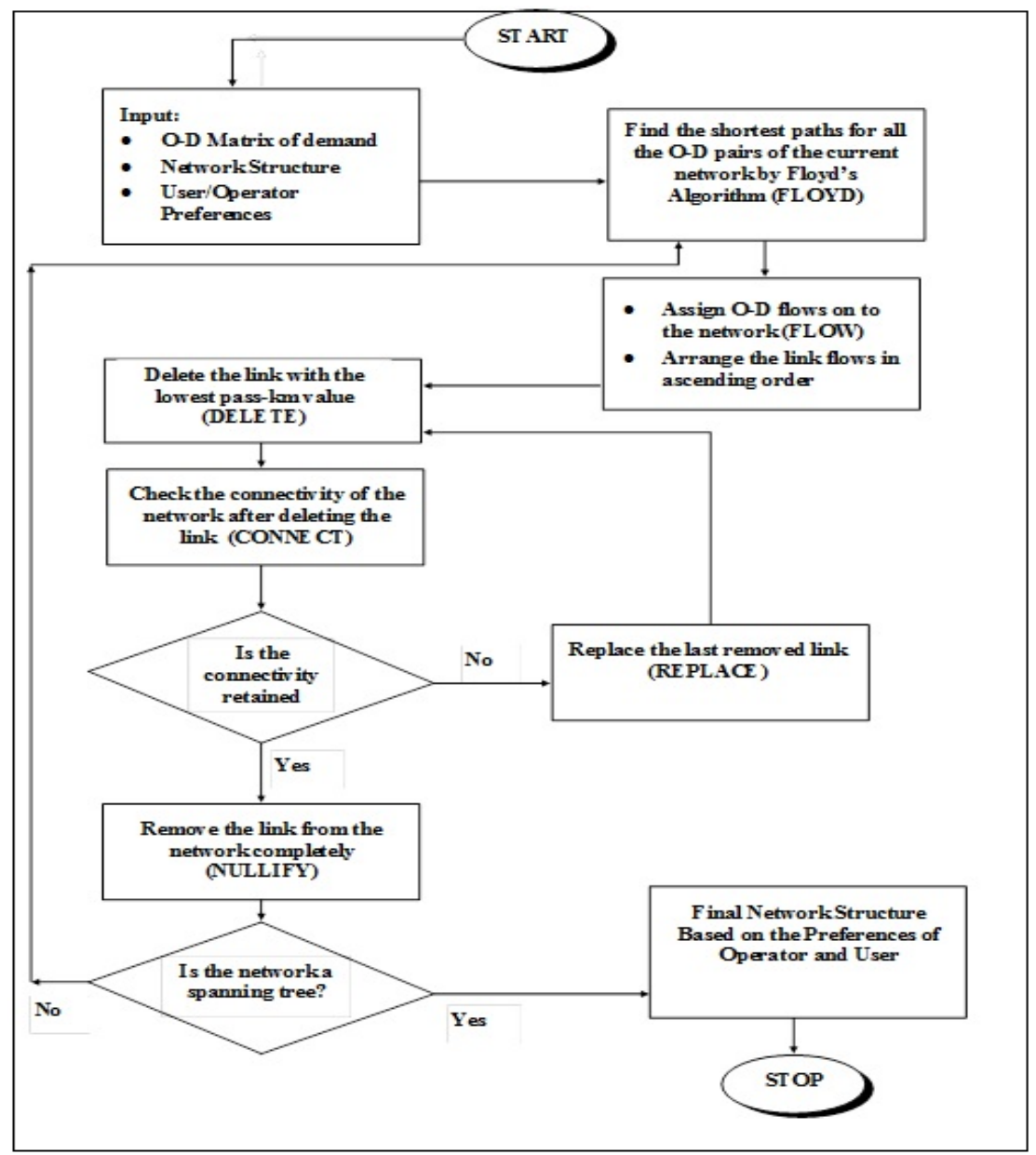




\section{Table 1. O-D Matrix for Demand (passengers/day)}

\begin{tabular}{|c|c|c|c|c|c|c|c|c|c|c|c|c|c|c|c|}
\hline $\mathbf{A}$ & 1 & 2 & 3 & 4 & 5 & 6 & 7 & 8 & 9 & 10 & 11 & 12 & 13 & 14 & 15 \\
\hline B & 16 & 17 & 18 & 19 & 20 & 21 & 22 & 23 & 24 & 25 & 26 & & & & \\
\hline $1 \mathrm{a}$ & 0 & 2 & 5 & 6 & 72 & 2 & 3 & 11 & 11 & 11 & 10 & 2 & 46 & 3 & 13 \\
\hline $1 b$ & 2 & 5 & 22 & 188 & 2 & 2 & 4 & 1 & 3 & 1 & 18 & & & & \\
\hline $2 a$ & 2 & 0 & 9 & 4 & 10 & 2 & 31 & 3 & 6 & 6 & 6 & 2 & 34 & 4 & 20 \\
\hline $2 b$ & 3 & 5 & 15 & 143 & 1 & 2 & 4 & 2 & 4 & 1 & 2 & & & & \\
\hline $3 a$ & 1 & 1 & 0 & 33 & 18 & 5 & 18 & 3 & 10 & 17 & 8 & 3 & 113 & 22 & 356 \\
\hline $3 b$ & 30 & 12 & 24 & 186 & 2 & 3 & 7 & 4 & 19 & 1 & 20 & & & & \\
\hline $4 a$ & 1 & 1 & 70 & 0 & 67 & 33 & 13 & 5 & 11 & 15 & 9 & 3 & 90 & 10 & 83 \\
\hline $4 b$ & 11 & 9 & 26 & 200 & 2 & 3 & 6 & 3 & 11 & 2 & 22 & & & & \\
\hline $5 a$ & 13 & 2 & 33 & 57 & 0 & 14 & 12 & 54 & 51 & 76 & 44 & 9 & 283 & 15 & 69 \\
\hline $5 b$ & 10 & 22 & 91 & 645 & 6 & 8 & 16 & 5 & 15 & 3 & 52 & & & & \\
\hline $6 a$ & 0 & 0 & 8 & 27 & 13 & 0 & 25 & 3 & 8 & 14 & 7 & 2 & 96 & 4 & 15 \\
\hline $6 b$ & 2 & 5 & 19 & 113 & 1 & 1 & 3 & 1 & 3 & 1 & 8 & & & & \\
\hline $7 a$ & 1 & 1 & 14 & 5 & 5 & 11 & 0 & 2 & 9 & 29 & 7 & 3 & 273 & 6 & 19 \\
\hline $7 b$ & 3 & 6 & 23 & 113 & 1 & 1 & 4 & 1 & 3 & 1 & 7 & & & & \\
\hline $8 \mathbf{a}$ & 5 & 2 & 13 & 11 & 130 & 5 & 11 & 0 & 186 & 54 & 152 & 17 & 218 & 13 & 47 \\
\hline $8 b$ & 8 & 21 & 87 & 689 & 6 & 8 & 16 & 5 & 13 & 4 & 59 & & & & \\
\hline $9 a$ & 0 & 0 & 2 & 1 & 6 & 1 & 3 & 9 & 0 & 26 & 1677 & 10 & 79 & 3 & 9 \\
\hline $9 b$ & 2 & 4 & 16 & 93 & 1 & 1 & 3 & 1 & 2 & 0 & 6 & & & & \\
\hline $10 \mathrm{a}$ & 0 & 0 & 3 & 1 & 7 & 1 & 6 & 2 & 21 & 0 & 15 & 3 & 1054 & 9 & 17 \\
\hline $10 \mathrm{~b}$ & 4 & 7 & 25 & 100 & 1 & 1 & 3 & 1 & 4 & 1 & 5 & & & & \\
\hline $11 a$ & 0 & 0 & 2 & 1 & 5 & 1 & 2 & 7 & 1624 & 18 & 0 & 13 & 58 & 2 & 7 \\
\hline $11 b$ & 2 & 3 & 13 & 78 & 1 & 1 & 2 & 1 & 2 & 0 & 5 & & & & \\
\hline $12 \mathrm{a}$ & 0 & 0 & 3 & 1 & 5 & 1 & 4 & 4 & 47 & 21 & 64 & 0 & 165 & 5 & 14 \\
\hline $12 b$ & 3 & 6 & 22 & 115 & 1 & 1 & 3 & 1 & 3 & 1 & 7 & & & & \\
\hline $13 a$ & 0 & 0 & 14 & 5 & 20 & 7 & 44 & 7 & 47 & 771 & 35 & 20 & 0 & 69 & 98 \\
\hline $13 b$ & 25 & 40 & 125 & 427 & 3 & 6 & 16 & 4 & 18 & 1 & 20 & & & & \\
\hline $14 a$ & 0 & 0 & 9 & 2 & 3 & 1 & 3 & 1 & 6 & 22 & 5 & 2 & 237 & 0 & 130 \\
\hline $14 \mathrm{~b}$ & 58 & 6 & 16 & 73 & 1 & 1 & 3 & 2 & 14 & 1 & 7 & & & & \\
\hline $15 a$ & 1 & 1 & 191 & 21 & 20 & 4 & 13 & 6 & 23 & 54 & 19 & 7 & 414 & 160 & 0 \\
\hline $15 b$ & 514 & 37 & 58 & 416 & 3 & 7 & 17 & 10 & 91 & 3 & 42 & & & & \\
\hline $16 a$ & 0 & 0 & 9 & 2 & 3 & 1 & 2 & 1 & 5 & 12 & 4 & 1 & 100 & 69 & 124 \\
\hline $16 \mathrm{~b}$ & 0 & 9 & 11 & 82 & 1 & 1 & 4 & 2 & 32 & 1 & 8 & & & & \\
\hline $17 \mathrm{a}$ & 0 & 0 & 6 & 2 & 7 & 2 & 5 & 3 & 11 & 25 & 10 & 3 & 191 & 8 & 31 \\
\hline $17 b$ & 11 & 0 & 56 & 713 & 5 & 19 & 90 & 8 & 9 & 2 & 26 & & & & \\
\hline $18 \mathrm{a}$ & 0 & 0 & 5 & 23 & 10 & 2 & 6 & 4 & 14 & 28 & 12 & 4 & 193 & 7 & 21 \\
\hline $18 b$ & 4 & 18 & 0 & 2222 & 5 & 14 & 45 & 7 & 5 & 2 & 30 & & & & \\
\hline $19 a$ & 1 & 1 & 13 & 6 & 27 & 5 & 11 & 12 & 33 & 44 & 29 & 8 & 256 & 13 & 51 \\
\hline $19 b$ & 12 & 89 & 864 & 0 & 72 & 70 & 230 & 34 & 26 & 11 & 200 & & & & \\
\hline $20 \mathrm{a}$ & 0 & 0 & 1 & 1 & 2 & 0 & 1 & 1 & 2 & 3 & 2 & 1 & 15 & 1 & 4 \\
\hline
\end{tabular}


Table 1. Continued

\begin{tabular}{|c|c|c|c|c|c|c|c|c|c|c|c|c|c|c|c|}
\hline $20 \mathrm{~b}$ & 1 & 5 & 17 & 646 & 0 & 10 & 10 & 2 & 2 & 3 & 79 & & & & \\
\hline $21 \mathrm{a}$ & 0 & 0 & 1 & 1 & 2 & 0 & 1 & 1 & 3 & 4 & 3 & 1 & 24 & 1 & 5 \\
\hline $21 b$ & 1 & 16 & 36 & 461 & 8 & 0 & 107 & 6 & 3 & 2 & 22 & & & & \\
\hline $22 a$ & 0 & 0 & 2 & 1 & 3 & 1 & 2 & 1 & 4 & 6 & 3 & 1 & 39 & 2 & 8 \\
\hline $22 b$ & 2 & 46 & 71 & 942 & 5 & 64 & 0 & 16 & 5 & 2 & 20 & & & & \\
\hline $23 a$ & 0 & 0 & 2 & 1 & 2 & 0 & 1 & 1 & 3 & 3 & 2 & 1 & 21 & 3 & 11 \\
\hline $23 b$ & 3 & 10 & 25 & 322 & 2 & 8 & 36 & 0 & 15 & 3 & 36 & & & & \\
\hline $24 a$ & 0 & 0 & 14 & 4 & 8 & 2 & 4 & 3 & 11 & 21 & 10 & 3 & 145 & 32 & 102 \\
\hline $24 b$ & 63 & 16 & 28 & 344 & 3 & 6 & 17 & 21 & 0 & 3 & 41 & & & & \\
\hline $25 a$ & 0 & 0 & 1 & 0 & 1 & 0 & 0 & 0 & 1 & 1 & 1 & 0 & 5 & 1 & 2 \\
\hline $25 b$ & 1 & 2 & 5 & 66 & 2 & 2 & 3 & 2 & 2 & 0 & 459 & & & & \\
\hline $26 a$ & 1 & 1 & 9 & 5 & 14 & 2 & 4 & 7 & 14 & 15 & 13 & 3 & 79 & 8 & 34 \\
\hline $26 b$ & 8 & 21 & 75 & 1299 & 57 & 21 & 32 & 24 & 20 & 480 & 0 & & & & \\
\hline
\end{tabular}

Note: The demand from each node is given in two rows ( $a$ and $b$ )

Figure 3. Optimal Spanning Tree Regional Bus Transit Network

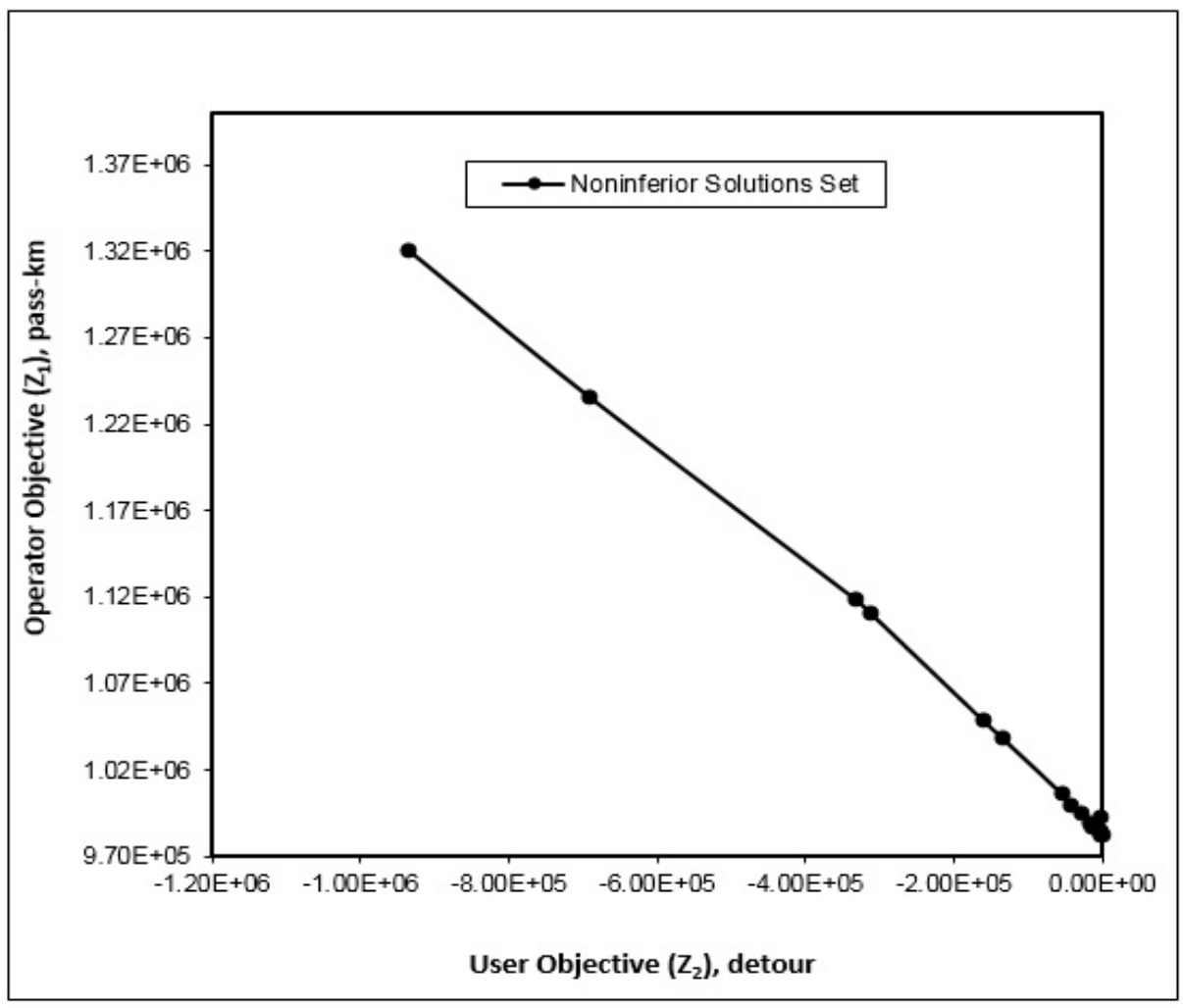


Table 2. Passenger Flow Concentration Results

\begin{tabular}{|l|l|l|l|l|}
\hline Iteration & $\begin{array}{l}\text { Total Passenger-km (Operator } \\
\text { objective) } \mathbf{Z}_{\mathbf{1}}\end{array}$ & $\begin{array}{l}\text { Total Detour (Passenger } \\
\text { Objective), } \mathbf{Z}_{2}\end{array}$ & $\begin{array}{l}\text { Link } \\
\text { Removed }\end{array}$ & No. of Links \\
\hline 1 & 982146 & $-0.000000 \mathrm{E}+00$ & $1-2$ & 40 \\
\hline 2 & 992344 & $-0.546340 \mathrm{E}+03$ & $11-12$ & 39 \\
\hline 3 & 982806 & $-0.127064 \mathrm{E}+04$ & $3-7$ & 38 \\
\hline 4 & 983634 & $-0.296289 \mathrm{E}+04$ & $21-25$ & 37 \\
\hline 5 & 983929 & $-0.343361 \mathrm{E}+04$ & $9-12$ & 36 \\
\hline 6 & 987664 & $-0.122930 \mathrm{E}+05$ & $20-21$ & 35 \\
\hline 7 & 989702 & $-0.164754 \mathrm{E}+05$ & $4-6$ & 34 \\
\hline 8 & 995137 & $-0.296137 \mathrm{E}+05$ & $14-16$ & 33 \\
\hline 9 & 1000310 & $-0.416708 \mathrm{E}+05$ & $18-22$ & 32 \\
\hline 10 & 1006262 & $-0.536925 \mathrm{E}+06$ & $16-24$ & 31 \\
\hline 11 & 1038353 & $-0.133472 \mathrm{E}+06$ & $4-5$ & 30 \\
\hline 12 & 1049158 & $-0.161083 \mathrm{E}+06$ & $15-16$ & 29 \\
\hline 13 & 1110213 & $-0.310558 \mathrm{E}+06$ & $5-8$ & 28 \\
\hline 14 & 1118955 & $-0.333074 \mathrm{E}+06$ & $25-26$ & 27 \\
\hline 15 & 1235755 & $-0.691584 \mathrm{E}+06$ & $17-22$ & 26 \\
\hline 16 & 1320462 & $-0.935651 \mathrm{E}+06$ & - & 25 \\
\hline
\end{tabular}

Figure 4. Variation of Operator's Objective with the No. of Links removed

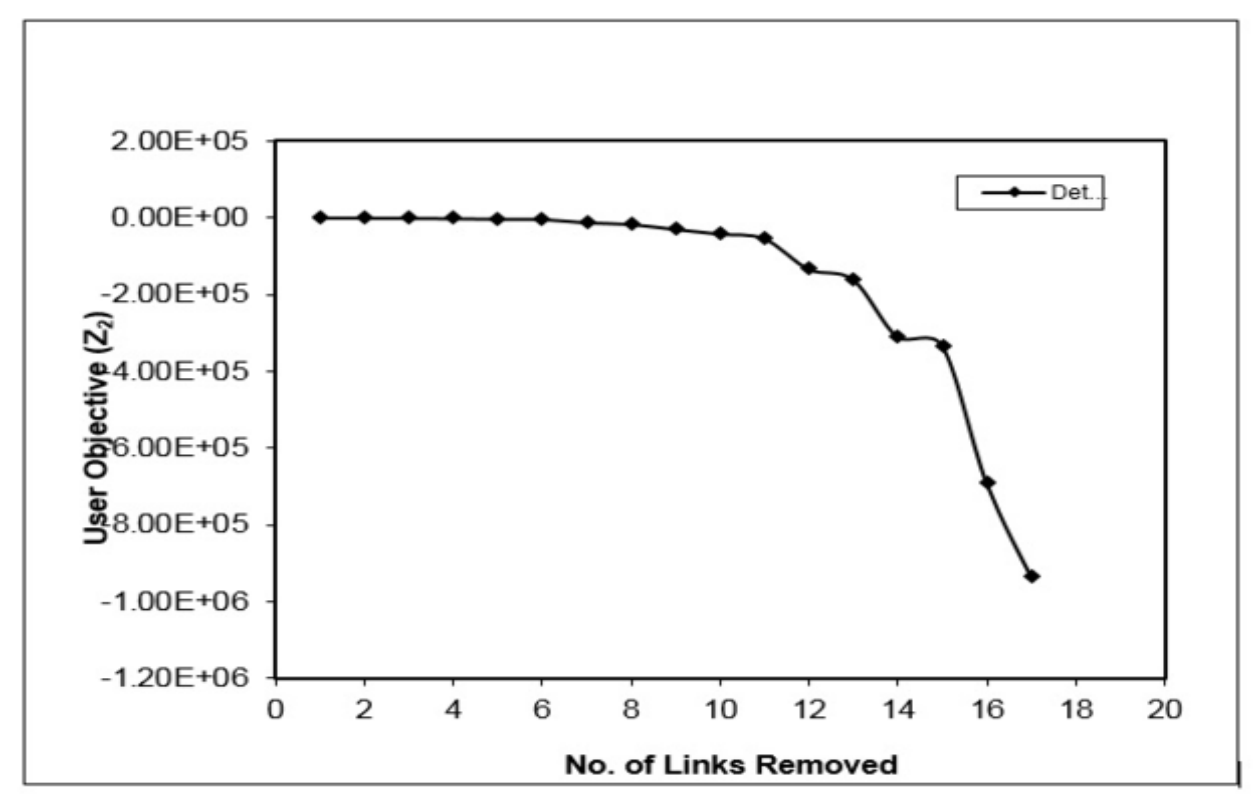


Figure 5. Variation of Users Objective with No. of Links Removed

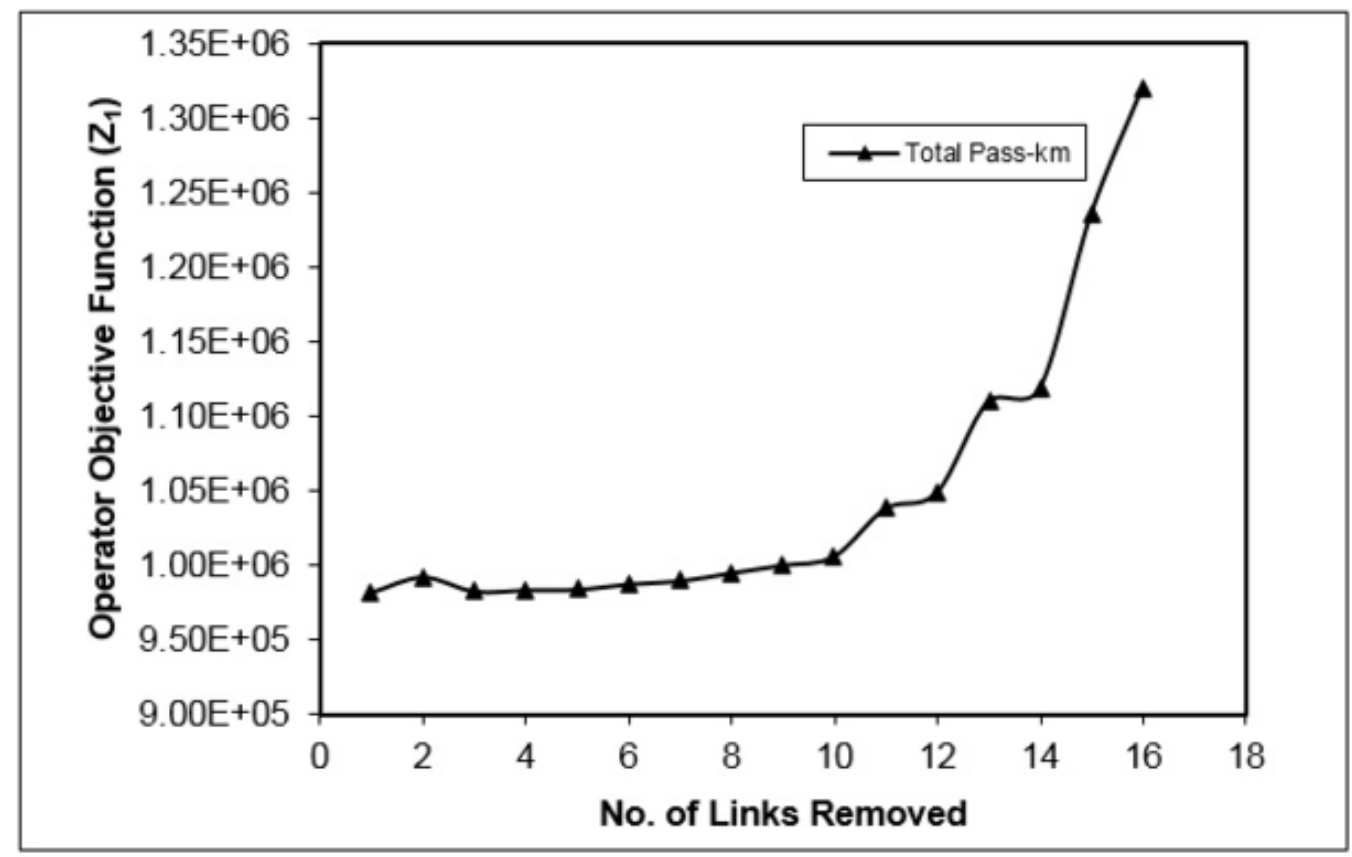

Figure 6. Noninferior Solution Space of User and Operator Objectives

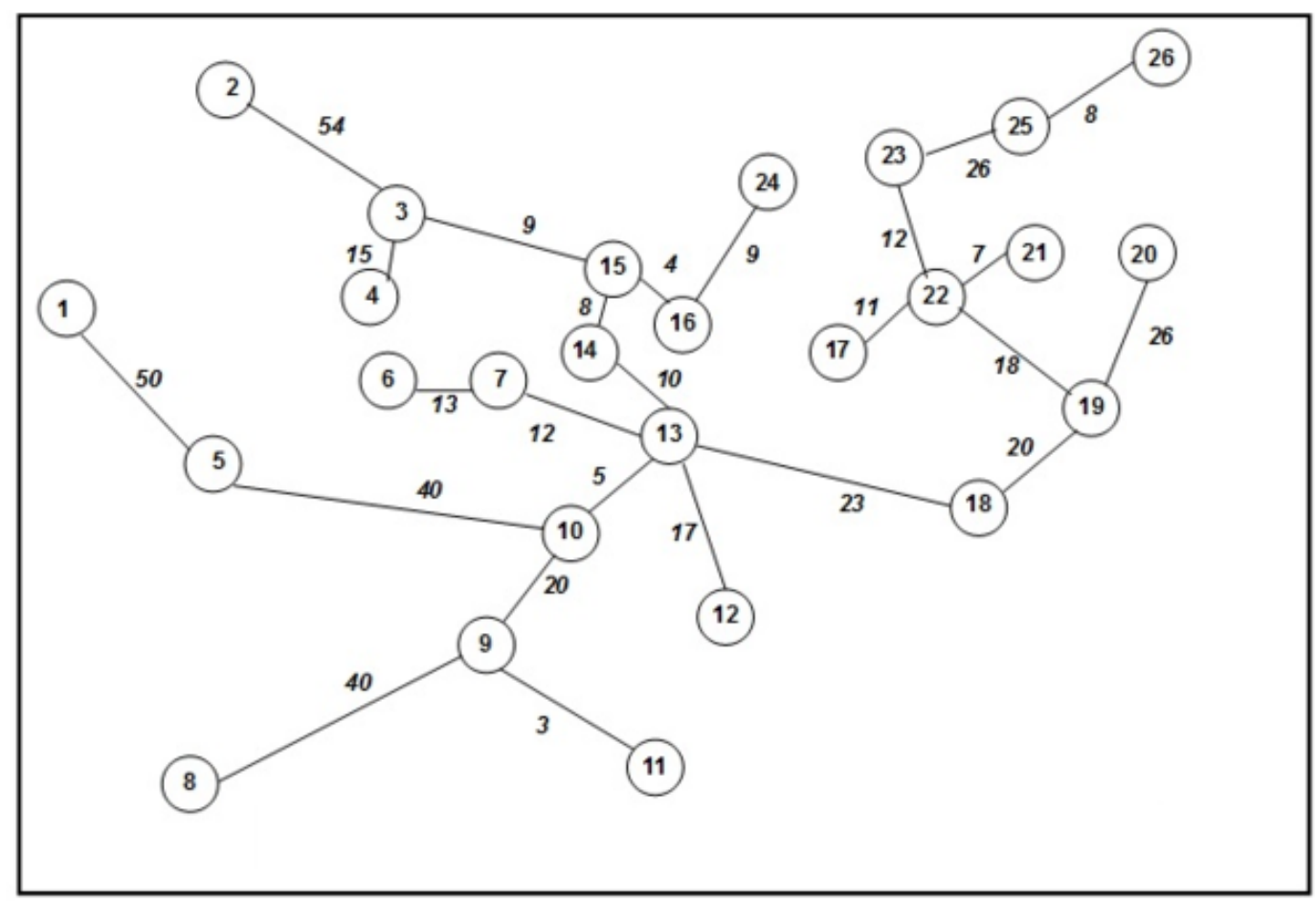




\section{CONCLUSION}

This paper presented a mathematical model for passenger flow concentration. Owing to the difficulty in solving 0-1 multiobjective programming problem a heuristic is proposed. The heuristic is evolved so as to maximize the operator objective while minimizing the passenger detour. This process is achieved by considering a link deletion strategy which finds solutions subject to the feasibility of the network which is represented by its connectivity. The selection of an appropriate network can be made based on the levels of passenger-km and detour that can be obtained from opinion surveys. The transit network to be used for the generation of the routes is decided on the basis of these two objective function values. 


\section{REFERENCES}

Billheimer, J. W., \& Gray, P. (1973). Network Design with Fixed and Variable Cost Elements. Transportation Science, 7(1), 49-74. doi:10.1287/trsc.7.1.49

Blue, V. J., Adler, J. L., \& List, G. F. (1997). Real-Time Multiple Objective Path Search for In-Vehicle Route Guidance Systems. Transportation Research Record: Journal of the Transportation Research Board, 1588(1), 10-17. doi:10.3141/1588-02

Carraresi, P., Malucelli, F., \& Pallottino, S. (1996). Regional Mass Transit Assignment with Resource Constraints. Transportation Research, 30B(2), 81-98. doi:10.1016/0191-2615(95)00027-5

Cohon, J. L. (1977). Multiobjective Programming and Planning. Academic Press.

Current, J., \& Marsh, M. (1993). Multiobjective Transportation Network Design and Routing Problems: Taxonomy and Annotation. European Journal of Operational Research, 65(1), 4-19. doi:10.1016/0377-2217(93)90140-I

Current, J. R., \& Min, H. (1986). Multiobjective Design of Transportation Networks: Taxonomy and Annotation. European Journal of Operational Research, 26(2), 187-201. doi:10.1016/0377-2217(86)90180-3

Deo, N. (1974). Graph Theory with Applications to Engineering and Computer Science. Prentice-Hall.

Dubois, D., Bel, G., \& Llibre, M. (1979). A Set of Methods in Transportation Network Synthesis and Analysis. The Journal of the Operational Research Society, 30(9), 797-808. doi:10.1057/jors.1979.190

Hasselström, D. (1981). Public Transportation Planning: A Mathematical Programming Approach. Department of Business Administration, University of Gothenburg.

Johnson, D. S., Lenstra, J. K., \& Rinnoy Kan, A. H. G. (1978). The Complexity of the Network Design Problems. Networks, 8(4), 279-285. doi:10.1002/net.3230080402

Kanafani, A. (1983). Transportation Demand Analysis. McGraw Hill Book Company.

Magnanti, T. L., \& Wong, R. T. (1984). Network Design and Transportation Planning: Models and Algorithms. Transportation Science, 18(1), 1-55. doi:10.1287/trsc.18.1.1

Marwah, B. R., Umrigar, F. S., \& Patnaik, S. B. (1984). Optimal Design of Bus Routes and Frequencies for Ahmedabad. Transportation Research Record: Journal of the Transportation Research Board, (994), 41-47.

Ramachandra Rao, K. (1998). A Methodology for Regional Bus Transit Network Planning (Unpublished Ph.D. thesis). Department of Civil Engineering, IIT, Kharagpur.

Rea, J. C. (1972). Designing Urban Transit Systems: An Approach to the Route Technology Selection Problem. Highway Research Record, 417, 48-59.

Steenbrink, P. A. (1974). Optimization of Transport Networks. John Wiley and Sons.

Wong, R. T. (1980). Worst Case Analysis of Network Design Problem Heuristics. SIAM Journal of Algebra and Discrete Methods, 1(1), 51-63. doi:10.1137/0601008

K. Ramachandra Rao is a Professor in Indian Institute of Technology Delhi. His is the Coordinator of Transportation Research and Injury Prevention Program (TRIPP). He has published widely in top transportation journals.

Subhro Mitra is an Associate Professor of Logistics and Supply Chain Management at University of North TexasDallas. His research interests include freight flow modeling, security in supply chain, asset management and life-cycle cost study, optimizing logistics network and facility location study.

Joseph Szmerekovsky is an Associate Dean/Professor of Transportation and Logistics in North Dakota State University. His research is primarily in the three areas of supply chain management, project management, and data analytics. 